\title{
A economia da bicicleta no Brasil: métodos e resultados
}

\section{The Brazilian bicycle economy: methods and findings}

\author{
Victor Andrade ${ }^{1}$, Pedro Bastos ${ }^{2}$, Filipe Marino ${ }^{3}$ \\ ${ }^{1}$ Universidade Federal do Rio de Janeiro, Rio de Janeiro - Brasil, victorandrade@fau.ufrj.br \\ 2Universidade Federal do Rio de Janeiro, Rio de Janeiro - Brasil, pedromacbast@gmail.com \\ 3Universidade Federal do Rio de Janeiro, Rio de Janeiro - Brasil, filipemarino@gmail.com
}

\section{Recebido:}

9 de novembro de 2020

Aceito para publicação:

18 de setembro de 2021

Publicado:

20 de dezembro de 2021

Editor de área:

Antônio Nélson Rodrigues da Silva

Palavras-chave:

Economia da bicicleta.

Mobilidade por bicicleta.

Complexo econômico da bicicleta.

Keywords:

Bicycle economics.

Bicycle mobility.

Economic bicycle complex.

DOI:10.14295/transportes.v29i4.2491

\begin{abstract}
RESUMO
Este artigo apresenta os métodos e resultados preliminares de um estudo exploratório realizado para mapear, caracterizar e monetizar a economia da bicicleta, representada neste trabalho pelo conceito de "complexo econômico". Compreender em que medida a bicicleta constitui ou é constituída por atividades econômicas específicas (e suas interrelações) é fundamental para um diagnóstico do seu potencial econômico e, também, para a produção de dados que possam subsidiar nichos de pesquisa científica no tema, elaboração de políticas públicas e planos de negócio, dentre outros. Com base em revisão de literatura nacional e internacional, foi definido uma matriz de dimensões, temáticas e indicadores, apontando para cada uma delas caminhos possíveis para extração e mensuração de dados. A partir deste arcabouço metodológico, o trabalho apresentou quatro dimensões do complexo econômico da bicicleta: 1) Cadeia Produtiva, 2) Políticas Públicas, 3) Transporte, 4) Atividades Relacionadas. Além de trazer resultados baseados em testes de métodos, esse artigo também indica recomendações e conclusões para aprimoramento deste arcabouço.
\end{abstract}

\begin{abstract}
This article presents the methods and preliminary results of an exploratory study to map, characterize, and monetize the bicycle economy, represented in this work by the concept of "economic complex." The main output is to understand the extent to which the bicycle constitutes or is constituted by specific economic activities (and their interrelations). Therefore, it will be possible to identify the bicycle economic potential and, also, to offer data that can subsidize niches of scientific research on the theme, elaboration public policies and business plans, among others. A matrix of dimensions, themes, and indicators was defined based on a nation-al and international literature review, pointing out each possible path for data extraction and measurement. From this methodological framework, the work presented four dimensions of the bicycle economic complex: 1) Productive Chain, 2) Public Policies, 3) Transport, 4) Related Activities. In addition to bringing results based on method testing, this article also indicates recommendations and conclusions for improving this framework.
\end{abstract}

\section{INTRODUCÃO}

Perante a influência global de ideários urbanos orientados para a sustentabilidade ambiental, muitas cidades do Brasil e do mundo presenciaram um aumento da importância da bicicleta em suas políticas públicas de transporte neste início do século XXI (Andrade et al, 2016; Bastos, no prelo; Andrade e Quintanilha, 2020). Esse panorama vem animando e, ao mesmo tempo, fazendo emergir nichos econômicos associados a esse meio de locomoção (BBC, 2021) como forma de tornar as cidades mais resilientes e humanizadas (Fainstein, 2000; ONU Habitat, 
2012), mas também de gerar oportunidades de emprego, negócios, linhas de pesquisa e desenvolvimento tecnológico, dentre outras atividades.

Apesar da economia da bicicleta emergir com um setor promissor dentro da economia urbana, ainda são escassos os estudos sistêmicos que monitorem dados acurados sobre o tema. $\mathrm{Ou}$, mesmo, estudos que desenvolvam e apresentem metodologias eficazes para coleta de dados diante do desafio de adequação metodológica à realidade da participação da bicicleta na economia de cada cidade e, principalmente, à acessibilidade de dados.

A literatura especializada revela estudos pioneiros internacionais que contribuíram para indicar caminhos metodológicos e por vezes monetizáveis de mapeamento da economia da bicicleta. Em 2014 e 2016, a Federação Europeia de Ciclistas estimou que o uso da bicicleta na União Europeia alcançou um valor total de aproximadamente $€ 513$ bilhões/ano, com geração de 650 mil empregos diretos de tempo integral (2020). Já a pesquisa realizada pela Agência de Transporte do Estado de Vermont (2015), Estados Unidos, apontou que serviços relacionados ao transporte ativo - bicicleta e transporte a pé - tiveram impactos econômicos diretos de US\$27,8 milhões em lucros anuais, além de gerarem 1.095 empregos em atividades de comercialização. No Reino Unido, em 2011, a London School of Economics (2012) estimou a contribuição bruta da mobilidade por bicicleta para a economia britânica em $€ 2,9$ bilhões, sendo aproximadamente $€ 230$ per capita.

Inspirado nestes trabalhos, o estudo apresentado neste artigo também foi pioneiro ao ilustrar a participação da bicicleta na economia brasileira de maneira mais extensiva e complexa, avançando as contribuições prévias de Rosenberg Associados (2015) e da Tendências Consultoria Integrada (2013) em compreender modelos econômicos e regulatórios de incentivo e regras tributárias do setor de produção de bicicletas. Nossos objetivos foram de realizar a identificação das dimensões da economia da bicicleta no Brasil e de explorar caminhos metodológicos para coleta e caracterização dos dados. Utilizou-se o conceito de "complexo econômico" para conduzir o desenho do arcabouço metodológico, partindo-se da premissa de que as atividades econômicas não devem ser vistas separadamente, mas como parte de uma rede. Para este artigo, também apresentamos os resultados preliminares que encontramos para cada dimensão e recomendações para refinamento metodológico e articulação entre eles.

A relevância de realização deste trabalho foi motivada também pelo fato de o Brasil ser uma das maiores economias do mundo (a oitava maior em 2019, com produção de US\$ 3,22 trilhões em bens e serviços medida pela paridade do poder de compra), segundo dados do Banco Mundial (Amadeo, 2021; Forbes, 2021), tornando ainda mais instigante levantar números para posterior situação da bicicleta numa economia deste porte.

A coleta de dados foi realizada entre maio de 2017 e fevereiro de 2018 e se deu por vias primárias e secundárias. Destas últimas, é relevante destacar os dados públicos do governo federal brasileiro, a exemplo dos microdados da Relação Anual de Informações Sociais (RAIS), fornecidas pelo Ministério do Trabalho, e da Pesquisa Industrial Anual (PIA), realizada pelo Instituto Brasileiro de Geografia e Estatística (IBGE). Eles contribuíram para caracterizar, sobretudo, dados referentes à cadeia produtiva da bicicleta no Brasil e ressaltam a importância da transparência de dados para a formulação de produtos de interesse público, como este.

Deste modo, identificar a participação da bicicleta na economia brasileira é de suma importância não somente para caracterizar e mensurar as potencialidades e os desafios do setor, mas, principalmente, para colaborar na incidência em políticas públicas de transporte e de transparência de dados. Nossa opção em apresentar o passo a passo de mapeamento da economia da 
bicicleta também contribui para que pesquisadores, gestores e tomadores de decisão disponham de instruções para extração de dados concernentes à bicicleta nesta abordagem econômica.

Além desta introdução, o conteúdo deste artigo distribui-se em seis sessões. Na primeira delas, apresentamos o conceito e escopo da pesquisa a partir de uma breve discussão teórica. Do item 2 ao 6, foram apresentadas as dimensões mapeadas (Cadeia Produtiva; Políticas Públicas; Transporte; Atividades Afins), os métodos desenvolvidos para coleta de dados e os resultados preliminares. Nas considerações finais, sintetizamos o panorama de resultados, apontando recomendações para o refinamento da metodologia.

\section{ECONOMIA DA BICICLETA NO BRASIL: CONCEITO E ESCOPO METODOLÓGICO}

Nos termos de Farmer (2012), consideramos por "economia" um sistema complexo de componentes ou atividades que interagem entre si conformando uma rede. Daí o emprego do conceito de "complexo econômico" para explicar que a economia da bicicleta faz parte de uma gama de atividades econômicas articuladas entre si. Para operacionalizar o objeto de pesquisa, buscamos representar esse complexo a partir de uma matriz de dimensões, temáticas e indicadores que tornassem mais inteligíveis as lacunas associadas à economia da bicicleta para além de suas partes mais "óbvias", como as vantagens econômicas que proporcionam ao orçamento doméstico de uma família que opta pelo uso da bicicleta em detrimento de veículos motorizados ou, mesmo, ao número de empregos gerados na atividade de comércio, por exemplo, como foi o foco dos estudos realizados na Europa e nos Estados Unidos (LSE, 2012; Vermont Agency Of Transportation, 2012).

Para desenhar o escopo da pesquisa, buscamos o diferencial de expandir contribuições bibliográficas relevantes produzidas em âmbito nacional sobre o tema, como os relatórios "O uso de bicicletas no Brasil: qual o melhor modelo de incentivos?”, produzido pela Rosenberg Associados (2015), e “Análise Econômica do Setor de Bicicleta e suas regras tributárias”, produzida pela Tendências - Consultoria Integrada (2013), ao levantar o maior número de atividades econômicas existentes - em alguns casos, atividades sobrepostas, inclusive - para mapear tal complexo econômico da forma mais extensiva e compreensiva. Como mencionado na Introdução, também nos valemos das contribuições de trabalhos da European Cyclists' Federation (2016), com o relatório "The EU Cycling Economy", da Vermont Agency of Transportation (2012), com o estudo de impacto "Economic Impact of Bicycling and Walking in Vermont", e da London School of Economics (2012), com o relatório The British Cycling Economy - Gross Cycling Product Report.

Um desafio marcante ao longo desse processo foi avaliar em que medida as atividades econômicas identificadas estavam ou não contempladas por dados estatísticos oficiais, implicando a necessidade de se buscar métodos alternativos para coletar dados e, assim, superar tal limitação. Sabendo da relevância da economia informal no Brasil, outra questão foi reconhecer a desconsideração da informalidade da bicicleta, especialmente no tocante aos dados estatísticos oficiais. Outra limitação foi que, perante os diferentes métodos que empregamos para "preencher" essa matriz de dimensões, temáticas e indicadores, os resultados preliminares apresentaram temporalidades e espacialidades distintas, dificultando a uniformização desse arcabouço. Para a questão da temporalidade, o critério foi coletar os dados mais recentes disponíveis no momento de elaboração da pesquisa. 
Além disto, para conferir maior validação ao arcabouço criado, o trabalho foi desenvolvido por uma equipe multidisciplinar de pesquisadores coordenada pelo Laboratório de Mobilidade Sustentável (LABMOB) da Universidade Federal do Rio de Janeiro (UFRJ) em parceria com a Associação Brasileira do Setor de Bicicletas (Aliança Bike). Cada etapa de construção dessa metodologia foi acompanhada por um painel de discussão formado por vários agentes do setor público, setor privado e terceiro setor ligados à bicicleta no Brasil em seus diversos aspectos. Uma vez identificadas e compreendidas essas atividades a partir de revisão de literatura comparada com a observação participante dos pesquisadores, elas foram categorizadas em quatro dimensões (Cadeia Produtiva, Políticas Públicas, Transporte e Atividades Afins), constituídas por 15 temáticas associadas (Tabela 1 ).

Tabela 1 - Matriz do complexo econômico da bicicleta: dimensões e temáticas

\begin{tabular}{lllll}
\hline Dimensão & Cadeia Produtiva & Políticas Públicas & Transporte & Atividades Afins \\
\hline Temáticas & Fabricação & Infraestrutura de Circulação & Uso Pessoal & Cicloativismo \\
& Importação e Exportação & $\begin{array}{l}\text { Infraestrutura de Estacionamento } \\
\text { Sistema Público de Bicicletas }\end{array}$ & & Pesquisa e Inovação \\
& Comercialização e Distribuição & $\begin{array}{l}\text { Compartilhadas } \\
\text { Reparos }\end{array}$ & & Cicloturismo \\
& Aluguel & & Cicloempreendedorismo \\
Eventos Esportivos
\end{tabular}

Nos itens a seguir, seccionamos a apresentação do desenho desse complexo econômico para explicar didaticamente a trajetória percorrida para a construção propositiva dessas dimensões e temáticas, métodos designados e resultados preliminares. Uma reflexão mais articulada entre essas dimensões e temáticas será feita ao final do artigo.

\section{DIMENSÕES DA MATRIZ DO COMPLEXO ECONÔMICO DA BICICLETA}

\subsection{Cadeia produtiva}

A primeira dimensão foi intitulada Cadeia Produtiva e compreendeu todas as atividades que englobam o processamento de insumos para a produção da bicicleta como mercadoria e seu repasse ao consumidor. Contemplou cinco temáticas: Fabricação/Montagem; Importação/Exportação; Comercialização; Reparos; Aluguel (Tabela 2).

Consideramos a temática de Fabricação aquela responsável por agrupar atividades de fabricação de bicicleta (que podem incluir a montagem resultante da combinação de seus diversos componentes) e a fabricação desses componentes, ou seja, de peças e demais subconjuntos que compõem o produto "bicicleta". Os dados apontaram que o Brasil produziu mais de 5,1 milhões de bicicletas, atingindo a marca de $\mathrm{R} \$ 728,3$ milhões em 2015. Nesse mesmo ano, o país produziu freios, cubos, aros e raios, pedais, quadros e selins, além de outras peças e acessórios para bicicletas. A produção de mais de 40,5 milhões de componentes, peças e acessórios correspondeu a um valor superior a $\mathrm{R} \$ 134$ milhões, com mais de 7 mil pessoas empregadas. 0 estudo contabilizou 296 unidades fabris, com forte concentração nas regiões Sudeste (38,2\%) e Sul $(22,1 \%)$. A soma de todos os salários pagos gira em torno de $\mathrm{R} \$ 174$ milhões, com rendimento médio de $\mathrm{R} \$ 2.063,39$, variando entre os $\mathrm{R} \$ 948$ pagos no Estado do Maranhão e os R $2.421,27$ no Estado de São Paulo.

Em Importação/Exportação, apresentamos os dados das atividades de importação e exportação relacionados ao setor da bicicleta. Em um primeiro momento, foi necessário identificar as mercadorias relacionadas à economia da bicicleta e seus respectivos códigos no sistema de 
Nomenclatura Comum ao Mercosul (NCM). Uma vez identificadas, essas mercadorias foram classificadas entre bicicletas, peças e acessórios. Em 2017, o Brasil exportou 28.492 bicicletas e importou 157.659, com um valor total nominal de pouco mais de R\$ 859 mil e de R\$25,7 bilhões, respectivamente.

Tabela 2 - Métodos para cadeia produtiva

\begin{tabular}{|c|c|c|c|c|}
\hline Temática & Indicadores & Fonte de dados & Ano & Escala \\
\hline Fabricação & $\begin{array}{l}\text { Bicicletas produzidas; } \\
\text { Valor total bicicletas produzidas; } \\
\text { Peças e acessórios produzidos; } \\
\text { Valor total peças e acessórios } \\
\text { produzidos; } \\
\text { Pessoas empregadas; } \\
\text { Fábricas; } \\
\text { Salários pagos }\end{array}$ & $\begin{array}{l}\text { Relação Anual de Informa- } \\
\text { ções Sociais (RAIS), do } \\
\text { Ministério do Trabalho } \\
\text { Pesquisa Industrial Anual } \\
\text { (PIA), do Instituto Brasileiro } \\
\text { de Geografia e Estatística } \\
\text { (IBGE) }\end{array}$ & 2015 & $\begin{array}{l}\text { Estadual; Regional; } \\
\text { Nacional. }\end{array}$ \\
\hline $\begin{array}{l}\text { Importação/ } \\
\text { Exportação }\end{array}$ & $\begin{array}{l}\text { Bicicletas importadas e exporta- } \\
\text { das; } \\
\text { Valor total nominal (bicicletas); } \\
\text { Número de peças e acessórios; } \\
\text { Valor total nominal (peças e aces- } \\
\text { sórios) }\end{array}$ & $\begin{array}{l}\text { Ministério da Indústria, } \\
\text { Comércio Exterior e } \\
\text { Serviços }\end{array}$ & 2017 & Nacional \\
\hline Comercialização & $\begin{array}{l}\text { Estabelecimentos atacadistas e } \\
\text { varejistas; } \\
\text { Pessoas empregadas; } \\
\text { Receita (R\$) } \\
\text { Massa salarial (R\$) }\end{array}$ & $\begin{array}{l}\text { RAIS/MTE } \\
\text { Survey }\end{array}$ & 2017 & $\begin{array}{l}\text { Estadual; Regional; } \\
\text { Nacional. }\end{array}$ \\
\hline Reparos & $\begin{array}{l}\text { Estabelecimentos; } \\
\text { Empregos }\end{array}$ & $\begin{array}{l}\text { RAIS/MTE } \\
\text { Survey }\end{array}$ & $\begin{array}{l}\text { 2006-2016 (série } \\
\text { histórica); } 2016 \\
\text { (para os dados } \\
\text { coletados no } \\
\text { survey). }\end{array}$ & $\begin{array}{l}\text { Estadual; Regional; } \\
\text { Nacional. }\end{array}$ \\
\hline Aluguel & $\begin{array}{l}\text { Número de empresas } \\
\text { Número médio de aluguéis/ano } \\
\text { Valor cobrado (R\$) } \\
\text { Valor médio investido em manu- } \\
\text { tenção/ano (R\$) } \\
\text { Receita total (R\$) } \\
\text { Empregos gerados }\end{array}$ & $\begin{array}{l}\text { RAIS/MTE } \\
\text { Estudo de caso }\end{array}$ & 2017 & Capitais \\
\hline
\end{tabular}

As bicicletas importadas pelo Brasil chegaram principalmente da China, Taiwan, Camboja e Portugal, enquanto as bicicletas exportadas tiveram como destino primordialmente países como Paraguai, Uruguai, Bolívia, Chile e Angola. No que diz respeito a peças e acessórios, em 2017 foram importados 35,1 milhões de unidades, totalizando mais de US\$ 185,9 milhões de dólares (cerca de R $\$ 613,4$ milhões), enquanto foram exportadas 470.349 unidades, totalizando pouco mais de US\$1,4 milhão (R \$ 4,62 milhões) - considerando a cotação média do dólar, em 2017, a R\$ 3,31 (ADFN, 2021).

Em Comercialização, as atividades relacionadas à venda de bicicletas e acessórios dividiramse em duas ramificações de análise: comércio atacadista e comércio varejista. Nos dados de 2016, foram identificados 269 estabelecimentos atacadistas que empregavam 3.203 pessoas no total. Essa atividade possui perfil pouco disperso no país, porque está concentrada notadamente no Estado de São Paulo, que lidera o ranking nacional com 77 estabelecimentos. Dados levantados a partir de survey com uma dessas empresas, no ano de 2016, eles indicaram a distribuição de 89.163 peças ou equipamentos associados à bicicleta e receita de $\mathrm{R} \$ 14,8$ milhões aproximadamente, gerando 21 empregos diretos. 
Diferentemente do comércio atacadista, o comércio varejista se apresenta de maneira mais pulverizada pelo território nacional, estando presente em todas os Estados e na maior parte dos municípios. Em 2016, segundo dados da RAIS/MTE, o Brasil contava com 5.689 estabelecimentos do ramo do varejo, empregando 13.783 pessoas. A remuneração média no comércio varejista de bicicletas, peças e acessórios, em 2016, era de $\mathrm{R} \$ 1.245$, e a massa salarial total somou $\mathrm{R} \$ 205,9$ mil no mesmo ano.

Com apoio da Associação Brasileira do Setor de Bicicletas (Aliança Bike), que mantém uma lista de empresas varejistas associadas, foi aplicado um survey para caracterizar esta atividade através do contato on-line com 138 estabelecimentos. Os resultados mostraram que o faturamento médio no Brasil foi de $\mathrm{R} \$ 796$ mil em 2017. Destes, $22 \%$ tiveram faturamento entre $\mathrm{R} \$$ 50 mil e R\$ 200 mil. Outros 20\% faturaram entre R\$ 200 mil e R\$ 500 mil; apenas 1\% teve faturamento superior a $\mathrm{R} \$ 10$ milhões. Também foi identificado que 76,8\% das bicicletarias dispunham de até cinco trabalhadores em exercício profissional.

A temática de Reparos agrupou as atividades de conserto, restauro e arranjo de bicicleta, triciclo e outros veículos não motorizados. Em 2016, foram identificados 641 empregos e 399 estabelecimentos formais em todo o país. Ao contrário da Comercialização e, principalmente, da Fabricação/Montagem, o ramo de Reparos gerava proporcionalmente menos empregos. Em média, cada estabelecimento contava com 1,6 empregado, enquanto na fabricação e no comércio varejista a média era de 23,4 e 2,4, respectivamente. Outra característica importante é que a atividade de reparo tendia a ser realizada por muitos estabelecimentos comerciais, já que 76\% dos varejistas entrevistados para a temática de Comercialização afirmaram realizar conjuntamente este tipo de atividade.

A temática Aluguel considerou as atividades de locação realizada por empresas especializadas em uso particular temporário da bicicleta, destacadamente para fins turísticos e de lazer, e de forma avulsa (para Sistema de Bicicletas Públicas Compartilhadas, ver dimensão Políticas Públicas, no item 3). No levantamento realizado por esta pesquisa, foram identificados 99 estabelecimentos no total existentes no país, representando 11\% dos 886 estabelecimentos registrados no setor de aluguel de equipamentos recreativos e esportivos do IBGE. Considerando esse parâmetro, o Brasil teria aproximadamente 296 pessoas empregadas na atividade de aluguel de bicicletas, com uma massa salarial anual total de $\mathrm{R} \$ 4,5$ milhões.

As cidades do Rio de Janeiro e de São Paulo concentram o maior número de empresas de aluguel. Tal como percebido em Reparos, as atividades de Aluguel são prestadas de forma conjunta em 15\% dos estabelecimentos comerciais varejistas averiguados. Algumas empresas dedicadas ao serviço também funcionam por meio de parceria com redes de hotéis, vinculando o caráter turístico da atividade principalmente em localizações à beira-mar, como o Rio de Janeiro.

Estudo de caso realizado no Rio de Janeiro buscou aprofundar a realidade de três empresas do ramo, uma de grande e duas de pequeno porte. No primeiro caso, companhia com atuação no Rio de Janeiro através de parceria com 20 hotéis indicou 10 mil locações por ano com receita de $\mathrm{R} \$ 250$ mil ( $\mathrm{R} \$ 15$ por hora de uso), subtraídos $\mathrm{R}$ \$ 60 mil de gastos com manutenção, detendo apenas três empregos diretos apoiados transversalmente pela força de trabalho dos hotéis parceiros, sendo esta última não contabilizada pela pesquisa. Para os outros casos, percebeu-se outra realidade; embora o valor de aluguel seja o mesmo praticado pela empresa maior, as receitas e custos com manutenção chegaram a ser pelo menos 40 vezes menores. 


\subsection{Políticas públicas}

Na dimensão Políticas Públicas, agrupou-se as atividades econômicas associadas à abordagem da bicicleta na esfera pública em termos de provisão direta e indireta de infraestrutura. Essa dimensão contemplou três temáticas: Infraestrutura de Circulação e Sistema Público de Bicicletas Compartilhadas (Tabela 3).

Tabela 3 - Métodos para políticas públicas

\begin{tabular}{|c|c|c|c|c|}
\hline Temática & Indicadores & Fonte de dados & Ano & Escala \\
\hline Infraestrutura de Circulação & $\begin{array}{l}\text { Investimento estimado (R\$) } \\
\text { Vias cicláveis (km) } \\
\text { Custo médio de quilômetro implantado por } \\
\text { capital (R\$) }\end{array}$ & $\begin{array}{l}\text { Diário Oficial } \\
\text { Jornais }\end{array}$ & 2017 & $\begin{array}{l}\text { Capitais; } \\
\text { Regional; }\end{array}$ \\
\hline $\begin{array}{l}\text { Sistema Público de Bicicletas } \\
\text { Compartilhadas }\end{array}$ & $\begin{array}{l}\text { Número total de sistemas públicos de bicicletas } \\
\text { compartilhadas existentes no Brasil; } \\
\text { Número médio de usuários dos sistemas públicos } \\
\text { de bicicletas compartilhadas no Brasil por ano; } \\
\text { Valor médio investido para implantação do } \\
\text { sistema (R\$); } \\
\text { Valor médio investido em manutenção/ano do } \\
\text { sistema (R\$); } \\
\text { Número de empregos gerados pelo serviço; } \\
\text { Receita total gerada pelo serviço/ano (R\$) }\end{array}$ & $\begin{array}{l}\text { Websites oficiais } \\
\text { Estudo de caso }\end{array}$ & $\begin{array}{l}2016- \\
2017\end{array}$ & $\begin{array}{l}\text { Capitais; } \\
\text { Regional; } \\
\text { Nacional }\end{array}$ \\
\hline
\end{tabular}

A temática de Infraestrutura de Circulação compreendeu as atividades envolvidas na provisão e manutenção da infraestrutura cicloviária destinada ao deslocamento por bicicleta, tais como ciclovias, ciclofaixas e ciclorrotas. Essa atividade se mostra de responsabilidade direta do poder público - sobretudo da esfera municipal. 0 método empregado para coleta de dados teve como ponto de partida o valor da quilometragem da malha cicloviária pago em cada capital brasileira. Os dados obtidos, contudo, somavam diferentes tipologias, sem discriminar ciclofaixas, ciclorrotas e faixas compartilhadas.

Os custos médios para a implantação de Infraestrutura de Circulação por região do país foram obtidos por meio de fontes variadas onde houvesse indicativo do valor empregado na construção de vias cicláveis e de sua quilometragem correspondente. Por exemplo, a extensão (em $\mathrm{km}$ ) da malha cicloviária teve como fonte referencial a matéria publicada pelo portal de notícias G1 (18 fev. 2017), intitulada "Em 3 anos, malha cicloviária mais que dobra de tamanho nas capitais do país".

Os resultados encontrados para Infraestrutura de Circulação mostraram que o investimento total para a implantação da malha cicloviária brasileira somou um total de pouco mais de $\mathrm{R} \$ 1,2$ bilhão. Observa-se que Rio de Janeiro e São Paulo aparecem como as capitais que detêm a maior quilometragem em vias cicláveis e, consequentemente, onde é realizado o maior investimento, representando quase $45 \%$ do total investido no Brasil. Por outro lado, essas cidades também são as que menos investem por número total de habitantes, ocupando o quarto $(\mathrm{R} \$ 40,13)$ e o décimo-primeiro lugar ( $R \$ 25,47)$, respectivamente, entre as 27 capitais listadas. 0 destaque fica para Rio Branco $(\mathrm{R} \$ 111,42)$, Vitória $(\mathrm{R} \$ 84,55)$ e Brasília $(\mathrm{R} \$ 52,30)$.

Quando observados os contrastes entre grandes regiões, embora a Região Sudeste apresente o maior valor total investido, por outro lado, acaba apontando um investimento per capita não tão alto se aquele comparado às capitais das demais regiões por causa do seu grande contingente populacional. Nesse comparativo, a Região Centro-Oeste apresentaria os maiores níveis de investimento conforme à sua realidade populacional. 
Através da consulta ao Sistema de Custos de Obras e Serviços de Engenharia do Rio de Janeiro (Prefeitura do Rio de Janeiro, 2017), verificou-se o caso específico dessa cidade para fins de obtenção mais precisa dos valores aqui apresentados. 0 estudo estimou um custo médio de $\mathrm{R} \$$ 450 mil por quilômetro, sendo que, para ciclovias, esse custo é de $\mathrm{R} \$ 2.415,33$ por quilômetro, enquanto o custo para a pavimentação se mostra 25 vezes maior, chegando ao valor de $\mathrm{R} \$$ $65.046,15$. 0 restante do valor empenhado inclui, portanto, outros elementos relacionados à ciclovia, como os custos de sinalização e iluminação, entre outras estruturas.

Por Sistema Público de Bicicletas Compartilhadas, consideramos o serviço homônimo operado por empresas do setor privado, não representando o mesmo escopo de utilização da bicicleta tratada na temática Aluguel, da dimensão Cadeia Produtiva. Para a obtenção de um panorama nacional relativo a essa atividade, mapeamos o número total de sistemas públicos existentes no Brasil, assim como sua abrangência em cada cidade através do número de estações e bicicletas que compunham cada um deles. Os dados foram levantados mediante múltiplas fontes, considerando principalmente os dados disponíveis na internet, como websites ou aplicativo para celular de cada sistema. Os dados relativos à movimentação financeira do setor foram obtidos por meio do contato com duas empresas operadoras do serviço às quais houve aplicação de survey on-line.

Os dados coletados referentes ao ano de 2017 indicaram a existência de 7.861 veículos distribuídos em 926 estações de bicicletas públicas, com maior concentração no Rio de Janeiro (1.951 bicicletas e 260 estações), São Paulo (1.951 bicicletas e 276 estações), Fortaleza ( 920 bicicletas e 73 estações) e Recife ( 800 bicicletas e 80 estações). Para melhor caracterização dessa atividade, foi realizado estudo de caso com duas empresas operadoras de sistemas públicos.

A Empresa 1, que opera 11 sistemas e com maior abrangência nacional, gerava 208 empregos diretos em 2017. 0 investimento na implantação do sistema custou R 80 milhões, em manutenção R 40 milhões, e receita média anual de R \$ 5,8 milhões. Já com a Empresa 2, levantamos dados sobre a operação do sistema em apenas uma das capitais brasileiras. Foram detectados 146.096 usuários cadastrados, 15 empregos diretos, 1.780 passes diários, 830 passes mensais, 60 passes anuais, e uma receita média anual de $\mathrm{R} \$ 196.920$.

\subsection{Transporte}

A dimensão Transporte levou em conta a participação econômica da bicicleta a partir do modo como ela é utilizada na esfera doméstica - uso pessoal da bicicleta nos deslocamentos cotidianos - e na esfera comercial - uso da bicicleta como meio de transporte para entregas. Nesta dimensão, são apresentadas duas temáticas: Uso Pessoal; Ciclologística (Tabela 4).

Em Uso Pessoal, consideramos a utilização doméstica da bicicleta como meio de transporte para movimentos pendulares e outras finalidades, tais como lazer e compras. 0 objetivo foi compreender as motivações do comportamento de viagem e os custos evitados com transporte na realidade de cinco famílias de cinco diferentes estratos socioeconômicos residentes na região metropolitana do Rio de Janeiro e em que pelo menos um dos membros tenha assumido ser usuário assíduo da bicicleta.

As famílias foram selecionadas a partir de indicação e a coleta de dados se deu através da aplicação de dois questionários presenciais com elas. 0 primeiro questionário, intitulado Perfil Familiar de Estratificação Socioeconômica e Consumo (USP, 2015), perfilou essas famílias 
seguindo uma hierarquia socioeconômica. Cada uma delas se encaixou em classes A (classe alta), B (classe média-alta), C (classe média), D (classe média baixa) e E (classe baixa).

Tabela 4 - Métodos para transporte

\begin{tabular}{lllll}
\hline Temática & Indicadores & Fonte de dados & Ano & Escala \\
\hline Uso Pessoal & Custos anuais evitados; & Estudo de caso & 2017 & Rio de Janeiro (região metropolitana) \\
& $\begin{array}{l}\text { Quilômetros pedalados por ano; } \\
\text { Participação percentual da bicicleta } \\
\text { nos modos de transporte utilizados; }\end{array}$ & & & \\
\hline Ciclologística & Estabelecimentos por tipo; & Estudo de caso & 2017 & São Paulo (capital) \\
& $\begin{array}{l}\text { Veículos por estabelecimento; } \\
\text { Ciclistas por estabelecimento; } \\
\end{array}$ & & & \\
& Entregas por dia; & & \\
\hline
\end{tabular}

As famílias A, B e C residiam em áreas centrais e/ou nobres da cidade de Niterói e Rio de Janeiro, enquanto a família D residia numa favela na periferia do Rio de Janeiro e a família E no município de Tanguá, na região metropolitana. Em seguida, foi aplicado um segundo questionário, inspirado em formulários prévios usados por Peter Næss (2002; 2012), com o objetivo de identificar as viagens semanais realizadas por todos os membros do domicílio, tanto por bicicleta como por outros meios.

Os custos evitados nas viagens realizadas com bicicleta foram calculados a partir dos gastos relacionados com cinco modos de transporte correspondentes ao mês de agosto de 2017: automóvel particular (padrão que utiliza 1 litro de gasolina a cada 9 quilômetros rodados, considerando o valor de $\mathrm{R} \$ 4,20$ para o litro na cidade do Rio de Janeiro); ônibus, considerando tarifabase vigente no Rio $(R \$ 3,60)$, em Niterói $(R \$ 3,70)$ e em Tanguá $(R \$ 4,00)$; Uber, preço calculado com base numa corrida entre as localidades informadas de origem e destino; e táxi, com preço calculado numa corrida não promocional de táxi entre as localidades informadas. Para os custos com automóvel, também foram considerados custos relacionados como valor de aquisição, seguro, imposto sobre a propriedade de veículos automotores, depreciação, licenciamento e seguro obrigatório.

Os resultados de Uso Pessoal mostraram que a participação semanal do uso da bicicleta tende a ser maior nas famílias de mais baixa renda (D e E) do que nos estratos mais altos (A, B e C). Enquanto nas famílias D e E a participação da bicicleta alcança $100 \%$ das viagens realizadas, esse percentual cai para 58\% na família A, 39\% na família B e 12\% na família C. Segundo os cálculos realizados, os custos anuais evitados com automóvel particular nas viagens realizadas por bicicleta variam entre $\mathrm{R} \$ 9.987,46$ na família A e R \$13.730,29, na família E. Num total, $\mathrm{R} \$ 12.831,68$ é a economia média no orçamento de uma família em que ao menos um dos membros trocou o carro pela bicicleta nas realidades investigadas. Além disto, 12.072 km é a distância que uma família de classe $\mathrm{D}$, formada por três pessoas, pedala anualmente.

A abordagem qualitativa dos resultados de Uso Pessoal diagnosticou que os casos das famílias D e E, por não disporem de outro meio de locomoção senão a bicicleta, se diferem dos demais casos na medida em que a utilização de outros modos alternativos de transporte parece ser mais acessível aos estratos mais altos.

Esse panorama também é contextualizado diretamente com a realidade socioespacial do Rio de Janeiro, onde a residência em determinadas áreas implica melhor acessibilidade a determinados modos de transporte que em outras áreas. Também é importante mencionar que o pa- 
drão de deslocamento é mais variante e complexo - isto é, maior número de viagens para variados fins - nos três estratos mais altos do que nos dois últimos casos, que declararam seguir uma rotina pendular direta entre casa e trabalho. Esse dado coincide com as premissas de Banister (2008) e Zhang e Acker (2017) sobre o comportamento de viagem entre estratos mais altos tender a ser mais variado.

Na temática Ciclologística, considerou-se a utilização da bicicleta como meio de transporte para a prestação de serviços e entrega de mercadorias. 0 meio de investigação utilizado foi a realização de estudo de caso com aplicação de entrevista com lojistas e comerciantes instalados no Bom Retiro, em São Paulo.

Dada a alta concentração de comércios e uso misto do solo, a região é reconhecida pelo volume de bicicletas em circulação fruto dessas atividades. 0 questionário aplicado foi inspirado em metodologia desenvolvida pela ONG Transporte Ativo, em 2011, sobre contagem de estabelecimentos comerciais que realizam entregas por bicicleta em Copacabana, no Rio de Janeiro.

Os resultados mostraram que 202 bicicletas e triciclos são utilizados diariamente, com 220 empregos diretamente ligados à bicicleta. Por dia, são realizadas 2.349 entregas no Bom Retiro. Em números percentuais, $20 \%$ dos estabelecimentos possuem funcionários exclusivos para entregas em bicicleta; $24 \%$ dos entregadores do bairro trabalham com bicicletas; $40 \%$ dos estabelecimentos realizam entregas havia menos de cinco anos; $96 \%$ dos estabelecimentos são proprietários das bicicletas utilizadas; $87 \%$ dos estabelecimentos optam pela bicicleta por critérios como "rapidez e praticidade".

\subsection{Atividades afins}

Nesta dimensão, denominamos por Atividades Afins aquelas cuja participação econômica da bicicleta esteja relacionada ao uso, consumo e/ou incentivo à bicicleta em cinco temáticas: Cicloativismo, Pesquisa e Inovação, Cicloempreendedorismo; Eventos Esportivos (Tabela 5).

Tabela 5 - Métodos para atividades afins

\begin{tabular}{|c|c|c|c|c|}
\hline Temática & Indicadores & Fonte de dados & Ano & Escala \\
\hline Cicloativismo & $\begin{array}{l}\text { Montante de investimento público e } \\
\text { privados ( } R \$ \text { ) } \\
\text { Número de pessoas ocupadas }\end{array}$ & Survey & 2016 & Regional; Nacional \\
\hline Pesquisa e Inovação & $\begin{array}{l}\text { Projetos } \\
\text { Pesquisadores } \\
\text { Financiamentos de pesquisa (R\$) }\end{array}$ & $\begin{array}{l}\text { Plataforma Lattes CNPq } \\
\text { Survey }\end{array}$ & $\begin{array}{l}2007- \\
2017\end{array}$ & Regional; Nacional \\
\hline Cicloempreendedorismo & $\begin{array}{l}\text { Investimento inicial (R\$); } \\
\text { Gastos/ano (R\$) } \\
\text { Empregos gerados } \\
\text { Receita/ano (R\$) }\end{array}$ & Estudo de caso & 2017 & São Paulo (SP) \\
\hline Eventos Esportivos & $\begin{array}{l}\text { Eventos; } \\
\text { Participantes; } \\
\text { Custo total dos eventos (R\$); } \\
\text { Gastos em hospedagem (R\$); } \\
\text { Total movimentado (R\$). }\end{array}$ & Estudo de caso & 2016 & $\begin{array}{l}\text { Araxá (MG); } \\
\text { Nacional }\end{array}$ \\
\hline
\end{tabular}

Por Cicloativismo, consideramos as atividades desempenhadas por organizações de iniciativa privada sem fins lucrativos e que prestam serviços de caráter público em apoio e promoção ao uso da bicicleta como meio de transporte. A coleta foi realizada em duas etapas: levantamento de organizações atualmente em atividade no Brasil (registradas ou não na União dos Ciclistas do Brasil - UCB) e aplicação de survey on-line. 
Os resultados de Cicloativismo indicaram a existência de 55 entidades ativas atuantes no Brasil em 2016. Aproximadamente 70\% delas haviam sido fundadas a partir de 2010 e $49 \%$ possuíam Cadastro Nacional de Pessoa Jurídica. Em 2016, essas entidades receberam em torno de $\mathrm{R} \$ 5,1$ milhões em receitas provenientes de financiamento público e privado, ou ainda da venda de produtos e da promoção de eventos.

Apesar da prevalência do trabalho não remunerado, mais de R\$ 1,3 milhão em 2016 foram desembolsados para o pagamento de pessoas ocupadas nessa atividade. Chamou a atenção que $90,57 \%$ da receita total das organizações e coletivos esteja concentrada na Região Sudeste do país, onde se localizam as maiores capitais, como Rio e São Paulo, e que $87 \%$ das receitas sejam oriundas de programas de financiamento exclusivamente privado.

A temática Pesquisa e Inovação reuniu as atividades associadas à produção científica universitária em que a bicicleta tivesse participação como objeto direto ou indireto de estudo. A coleta foi realizada em duas etapas: levantamento de projetos, artigos e pesquisadores envolvidos com o tema da mobilidade por bicicleta na base Plataforma Lattes, operada pelo Conselho Nacional de Desenvolvimento Científico e Tecnológico (CNPq) do Brasil; e aplicação de questionário online com os coordenadores de pesquisa levantados no intuito de se obter informações mais precisas a respeito de seus respectivos projetos.

De acordo com os dados encontrados para Pesquisa e Inovação, entre 2007 e 2017 foram realizados 124 projetos de pesquisa centrados na bicicleta no Brasil. Esses projetos se distribuíam em 16 das 27 Unidades da Federação e envolveram 270 pesquisadores, considerando doutores, mestres, doutorandos, mestrandos e estudantes de graduação. Ao todo, foram mobilizados cerca de $\mathrm{R} \$ 3,7$ milhões para o financiamento dessas pesquisas. A maioria dos projetos desenvolvidos na década investigada se localizam nas regiões Sudeste e Sul, com destaque para São Paulo (29), Santa Catarina (21), Rio de Janeiro (19) e Paraná (17), sendo que o Estado de São Paulo concentrou o maior valor de financiamento, totalizando aproximadamente R 1,9 milhão, seguido por Paraná ( $\mathrm{R}$ \$ 646.200) e Rio de Janeiro ( $\$$ \$ 491.200).

A temática de Cicloempreendedorismo correspondeu à atividade na qual a bicicleta, enquanto meio de transporte, é utilizada como objeto central para práticas empreendedoras, gerando renda e emprego, excetuando-se as práticas que a utilizam em imagem ou representações artísticas, a exemplo do uso cenográfico em atividades comerciais e afins. Essa temática foi uma das que mais apresentaram possibilidades de exploração, tendo em vista a diversidade de modelos de negócio nesse perfil. Por uma escolha metodológica, optamos por realizar estudo de caso sobre um modelo de negócio conhecido por bike café, localizado na cidade de São Paulo.

Nos últimos anos, a ampliação da cultura da bicicleta tem impulsionado diferentes tipos de Cicloempreendedorismo. A bicicleta como objeto central de práticas empreendedoras é observada no mercado editorial, em aplicativos para celular, vestuário e agências de turismo, assim como food bikes e bike cafés. Para mensurar essa temática, realizamos estudo de caso para entender o funcionamento e os indicadores econômicos do modelo de cicloempreendimento conhecido pelo perfil de bike café.

O bike café é um modelo de negócio multifuncional que congrega varejo de acessórios e equipamentos focados no ciclismo urbano, oficina mecânica, vestiários, além da parte gastronômica. Para ilustrar o caso, foi escolhido um cicloempreendimento na Zona Oeste de São Paulo. Inaugurado em 2013, o café pioneiro teve investimento inicial de R 700 mil reais, operava com oito funcionários empregados, tinha receita mensal de $\mathrm{R} \$ 60$ mil e gastos gerais mensais de $\mathrm{R} \$ 55$ mil, com um lucro aproximado de $\mathrm{R} \$ 60$ mil ao ano. 
A temática de Eventos Esportivos compreendeu todo tipo de torneio, competição, solenidade etc. no qual a bicicleta aparece como razão direta ou indireta. Nesta seção, foram analisados especificamente os eventos esportivos ligados à bicicleta. Esses eventos foram realizados em todo o Brasil, especialmente os circuitos competitivos de modalidades específicas, tais como mountain bike, cross-country, bicicross, na estrada etc.

Durante o ano de 2016, foram realizados 203 Eventos Esportivos oficiais ligados à bicicleta no Brasil, segundo dados da Confederação Brasileira de Ciclismo. Para a estimativa do montante gerado/consumido nesses eventos, foram levantadas as informações referentes à Copa Internacional de Mountain Bike do ano de 2017, que serviram como valor de referência para as nossas estimativas.

A Copa Internacional de Mountain Bike do ano de 2017 foi realizada em quatro etapas sediadas cada qual em uma cidade (Araxá, São João Del Rey, Congonhas-MG, e São Paulo-SP), contando com o total de 4.100 participantes, um custo médio per capita de R\$457,00 e total de $\mathrm{R} \$ 1.873 .700,00$. Para os eventos em âmbito nacional, foi realizado um levantamento de 40 dos 203 eventos que ocorreram no Brasil em 2016 (19,7\%). Desses 40 eventos, pode ser identificada a quantidade de participantes em 15. A partir dessa informação, considerou-se uma média estimada de 185 participantes por evento, totalizando 37.555 participantes em todo o Brasil. Considerando o custo de média per capita de $\mathrm{R} \$ 457$ aferido no estudo de caso, o custo total estimado em Eventos Esportivos no Brasil alcançaria valor da ordem de R\$17,1 milhões.

\section{CONSIDERAÇÕES FINAIS: LIMITAÇÕES E RECOMENDAÇÕES}

Os resultados apresentados neste artigo constituíram o primeiro passo para se explorar o papel da economia da bicicleta no Brasil diante do avanço promissor desse veículo nos deslocamentos cotidianos. 0 que se pode verificar deste mapeamento é de que se trata de uma economia predominantemente urbana, o que explica a ampliação do uso desse veículo nos grandes centros. Isto implica desafios de adequação metodológica ou conceitual para abarcar também a economia da bicicleta nos espaços rurais e, também, nos setores informais, nos quais há maiores barreiras à identificação e extração de dados para dimensionar uma economia em escala, de fato, nacional.

Além disto, consideramos essencial e relevante a contribuição deste exercício de mapear a economia da bicicleta devido à escassez de estudos que dimensionem compreensivamente as atividades econômicas que esse meio de transporte movimenta. À medida que o conceito de complexo econômico também indica a inter-relação entre essas atividades, torna-se ainda mais estratégico, num segundo momento, ampliar a articulação dos dados entre essas atividades para orientar a estruturação de programas e ações governamentais em prol da bicicleta, assim como para indicar nichos de negócios e empreendedorismo ainda pouco explorados.

Na dimensão Cadeia Produtiva, por exemplo, os laços estreitos entre as temáticas de Comercialização, Reparos e Aluguel confirmam esse aspecto de complexo econômico, indicados sobretudo nos dados coletados via aplicação de survey online, com estabelecimentos comerciais varejistas. Isto é, os varejistas tanto comercializam bicicletas, bem como oferecem serviços de locação e reparos, apontando para uma versatilidade na maneira como essas atividades são desempenhadas. 0 mesmo se pode dizer se correlacionada a temática de Comercialização com a de Cicloempreendedorismo.

$\mathrm{Na}$ dimensão de Políticas Públicas, é fundamental frisar o papel da transparência para formentar o acesso a dados - sobretudo, dados quantificados. Uma vez que a maioria dos 
resultados aos quais chegamos tiveram uma abordagem escalar municipal, nossa trajetória de pesquisa deparou com a irregularidade dos portais de transparência de dados das Prefeituras, por exemplo. Isto exigiu recorrermos a outras fontes bibliográficas e/ou realizar extrapolações de dados para produzir resultados quantificáveis. A Lei no 12.527, de 18 de novembro de 2011, que assegura o direito fundamental de acesso à informação como princípio da administração pública, ainda parece ter pouca aderência nestes casos, dificultando, inclusive, um maior monitoramento coletivo dos gastos públicos tanto nas políticas de bicicleta, como em outras rubricas.

Na dimensão Transporte, chamam a atenção as possibilidades futuras de mensuração da economia da bicicleta a partir do comportamento de viagem das famílias com a execução de cálculos de emissões evitadas de $\mathrm{CO}_{2}$ e de benefícios à saúde. Para o caso da saúde, diversos estudos já vêm mostrando a correlação cada vez mais promissora e otimista da redução de doenças crônicas não transmissíveis com o uso da bicicleta (Miraglia e Gouveia, 2014; Fajersztajn et al, 2016).

Contribuição recente de Brandão et al (2020) indicou métodos para calcular o impacto econômico do uso de bicicletas sobre a saúde, tendo como estudo de caso a frequência de utilização das bicicletas compartilhadas do Bike Itaú em todo o país. 0 indicador empregado, intitulado valor de vida estatístico, corresponde o quanto uma amostra representativa da população estaria disposta a pagar para salvar a vida de uma pessoa indeterminada, por exemplo, em função de uma política de intervenção capaz de reduzir o risco anual de mortalidade - da qual políticas públicas para bicicletas poderiam fazer parte.

Em Atividades Afins, não obstante as atividades listadas demonstrem pouca articulação entre si, por outro lado, constituem nichos econômicos promissores dada a sua versatilidade. Isto porque podem tanto intermediar e subsidiar formulação de políticas (Pesquisa e Inovação) e mediar disputas e tomadas de decisão (Cicloativismo), bem como experimentam, na prática, o desenvolvimento de serviços que centralizam a bicicleta como um meio de transporte não apenas ambientalmente sustentável, mas economicamente sustentável, também. Isto é, um meio de transporte capaz de gerar seus próprios "territórios" econômicos, como é o caso da temática de Cicloempreendedorismo.

Diante da experiência realizada, foi constatado que, para superar as dificuldades de obtenção de dados estatísticos oficiais - que nem sempre se mostram uniformizados para facilitar uma abordagem comparativa -, a alternativa mais estratégica é optar pela realização de estudos de casos.

Embora recorrer a esse método signifique limitar um conhecimento mais abrangente sobre a economia da bicicleta no país, visto que o restringe a determinadas espacialidades e contextos temporais que não correspondem à realidade econômica de um país tão diverso e continental como o Brasil, por outro lado, constitui mecanismos inteligentes de se explorar espaços pouco ou nada investigados e, a partir disto, estabelecer redes colaborativas entre parceiros aptos a fornecer informações que dificilmente seriam captadas em fontes documentais públicas.

Por fim, sublinhamos novamente que a metodologia desenvolvida buscou refletir um panorama bastante objetivo sobre as informações atualmente disponíveis, mas reconhecendo a pretensão ambiciosa em conseguir dimensionar a economia em escala nacional, especialmente diante da informalidade econômica.

Se, por um lado, esse panorama pode ter implicado no subdimensionamento dos dados, por outro contribuiu para caracterizar e levantar quantificações preliminares de um campo de conhecimento que está em emergência e cujos métodos de coleta deverão ser refinados em 
trabalhos futuros. Além disto, deve-se levar em consideração o dinamismo da economia e a aparição e renovação de atividades econômicas constantemente, exigindo um exercício de monitoramento para manter este arcabouço metodológico em dia com as transformações sociais e econômicas.

\section{AGRADECIMENTOS}

Os autores agradecem a Juciano Martins Rodrigues pela participação inestimável na coleta e análise de dados sobre cadeia produtiva; e a Marcela Kanitz e Letícia Quintanilha pelo apoio dado à elaboração desta pesquisa

\section{REFERÊNCIAS}

ADFN (2021). Cotação do Dólar em 2017. Disponível em: https://br.advfn.com/moeda/dolar/2017. Acesso em 30 mar. 2021.

Amadeo, K. (2021). Brazil's Economy and Its Effect on the United States. The Balance, Feb. 14, 2021. Disponível em: https://www.thebalance.com/brazil-s-economy-3306343. Acesso em 24 mar. 2021.

Andrade, V. e Quintanilha, L. (orgs.). (2020). Bicicletas nas cidades. Experiências de compartilhamento, diversidade e tecnologia. Belo Horizonte: Relicário.

Andrade, V. et al. (org.) (2016). Mobilidade por bicicleta no Brasil. Rio de Janeiro: PROURB.

Banister, D. (2008). The sustainable mobility paradigm. Transport Policy, Vol. 15, (2), Pp. 73-80.

Bastos, P.P.M. (no prelo). "A aceitação da mobilidade por bicicleta pelas narrativas dos jornais: uma análise do Rio de Janeiro e São Paulo”. In: CEBRAP. Estudos de mobilidade por bicicleta. São Paulo: CEBRAP.

BBC (2021). Explosão na demanda, aperto na oferta: como a pandemia impactou o mercado de bicicletas no Brasil. $B B C, 19$ fev. 2021. Disponível em: https://www.bbc.com/portuguese/brasil-56119561. Acesso em 21 mar. 2021.

Brandão, R. et al. (2020). Sistemas de bicicletas compartilhadas, atividade física e saúde. In: Andrade, V. e Quintanilha, L. (orgs.). Bicicletas nas cidades. Experiências de compartilhamento, diversidade e tecnologia. 1aa edição. Belo Horizonte: Relicário, p. 258-271.

Brasil (2011). Lei n. 12.527, de 18 de novembro de 2011. Lei de acesso à informação. Brasília: Senado Federal.

European Cyclists Federation (ECF) (2016). The EU cycling economy. Arguments for an integrated EU cycling policy. Report. December.

European Cyclists' Federation (ECF) (2014). Cycling Works. Jobs and Job Creation in the Cycling Economy. Report. October.

Fajersztajn, L. et al. (2016). Como as cidades podem favorecer ou dificultar a promoção da saúde de seus moradores? Estud. av., São Paulo, v. 30, n. 86, p. 7-27, Apr.

Farmer, J.D. (2012). Economic Needs to Treat The Economy As A Complex System. Working paper. May 3rd. Disponível em: https://www.ineteconomics.org/uploads/papers/farmer_berlinpaper.pdf. Acesso em 17 mar. 2021.

Fainstein, S.S. (2000). New Directions in Planning Theory. Urban Affairs Review, 35(4), 451-478.

Forbes (2018). Brazil: Best countries for Business 2018. Disponível em: https://www.forbes.com/places/brazil/?sh=39f257ef1cb0. Acesso em 24 mar. 2021.

G1 (2017). Em 3 anos, malha cicloviária mais que dobra de tamanho nas capitais do país. Economia, 18 de fev. 2017. Disponível em: http://g1.globo.com/econo-mia/noticia/em-3-anos-malha-cicloviaria-mais-que-dobra-de-tamanho-nas-capitais-dopais.ghtml. Acesso em 16 ago. 2017.

LABMOB e Aliança Bike (2018). Economia da Bicicleta no Brasil. Relatório de pesquisa, 2018. Disponível em: labmob.org. Acesso em 29 mai. 2018.

London School of Economics (LSE) (2011). The British Cycling Economy. 'Gross Cy-cling Product Report. Written by Alexander Grous.

Miraglia, S. e Gouveia, N. (2014). Custos da poluição atmosférica nas regiões metropolitanas brasileiras. Ciência \& Saúde Coletiva, 19 (10), p. 4141-4147.

Næss, P. Residential location influences travel - but how and why? Paper of the traffic days at Aalborg University, August 26-27, 2002.

Næss, P. Urban form and travel behavior: Experience from a Nordic context. The Journal of Transport and Land Use, v. 5, n. 2, pp. 21-45, 2012.

ONU Habitat (2012). Sustentabilidade urbana: impactos do desenvolvimento econômico e suas consequências sobre o processo de urbanização em países emergentes. Relatório. Brasília: Ministério do Meio Ambiente. Disponível em: https://antigo.mdr.gov.br/images/stories/ArquivosSNH/ArquivosPDF/Publicacoes/capacitacao/publicacoes/mobilidade_urbana.pdf.

Prefeitura do Rio de Janeiro (2017). Sistema de Custos de Obras e Serviços de Engenharia do Rio de Janeiro. Controladoria Geral do Município. Disponível em: https://carioca.rio/servicos/catalogo-do-sistema-de-obras-sistema-de-custo-deobras/. Acesso em 10 ago. 2017.

Rietveld, P. e Daniel, V. (2004). Determinants of Bicycle Use: Do Municipal Policies Matter? Transportation Research Part A, p. 531-550, 2004.

Rosenberg Associados (2015). O Uso de Bicicletas no Brasil: qual o melhor modelo de incentivo? Relatório. Abril. 
Tendências - Consultoria integrada (2013). Análise Econômica do Setor de Bicicletas e Suas Regras Tributárias. Relatório. Outubro.

Universidade de São Paulo (2015). FEA ajuda a criar novo Critério Brasil de Classificação Econômica. Notícias, 7 jan. Disponível em: https://www5.usp.br/noticias/sociedade/fea-ajuda-a-criar-novo-criterio-brasil-de-classificacao-economica/. Acesso em 21 mar. 2021.

Vasconcellos, E. (2000). Transporte Urbano nos Países em Desenvolvimento: reflexões e propostas. São Paulo: Annablume. Vermont Agency of Transportation (2012). Economic Impact of Bicycling and Walking in Vermont. Final Report, July 6.

Zhang, J. e Acker, V. (2017). Life-oriented travel behavior research: an overview. Transportation Research Part A, v. 104, p. 167178. 